\title{
Green preparation and structure elucidation of spiro indole derivatives using grindstone technique
}

\begin{abstract}
Grindstone Chemistry technique or Toda's solvent-free green method of grinding reactants together has been successfully applied for conducting multicomponent reaction of $1 \mathrm{H}$-indole-2,3-dione, malononitrile and 2-thioxo-4-thiazolidinone for the synthesis of Spiro indole derivatives. The reaction conditions have been studied and compared with conventional methods in terms of reaction time, yield and workup procedure. Grinding takes only 15 minutes to complete the reaction. The synthesized compounds have been characterized by IR, $1 \mathrm{HNMR}$, and ${ }^{13} \mathrm{CNMR}$ spectra.
\end{abstract}

Keywords: grindstone chemistry, solvent-free reaction, spiro indole derivatives, green synthesis, IR, ${ }^{1} \mathrm{HNMR},{ }^{13} \mathrm{CNMR}$
Volume I Issue 5 - 2017

\author{
Harshita Sachdeva, Sangeeta Sharma \\ Department of Chemistry, College of Arts, Science and \\ Humanities, India
}

Correspondence: Harshita Sachdeva, Department of Chemistry, College of Arts, Science and Humanities, Mody University of Science and Technology, Laxmangarh-3323।I (Sikar), Rajasthan, India, Email drhmsachdevaster@gmail.com, harshitasachdeva.cash@modyuniversity.ac.in

Received: August 03, 2017 | Published: October 27, 2017

\section{Introduction}

One of the most important goals of green chemistry is to redesign environmentally benign synthetic methods which produce less chemical waste. For several years, synthetic chemists have been familiar with the concept of step economy which is the drive to increase the brevity and efficiency of a synthesis by a reduction in the number of synthetic steps. A step economic synthesis has the potential to reduce the number and amount of reagents employed by reducing the number of synthetic steps. Grinding ${ }^{1}$ is simplified process for conducting the multi-component reactions whereby solvent-free chemical reactions occur by just grinding solid/solid, solid/liquid, or even liquid/liquid reactants together. Required activation energy is provided from friction of the reacting molecules. ${ }^{2}$ It is not only advantageous from the environmental point of view but also offers rate enhancement, less waste products and higher yields. Such reactions are simple to handle, reduce pollution, and comparatively cheaper to operate.

Grinding $^{3}$ is interesting because it is performed in the absence of solvent, leading to safe and eco-friendly synthesis. Furthermore, the proposed technique does not require external heating, leading to energy efficient synthesis and is more economical and eco-promising procedure in chemistry. Mechanical-induced breaking of molecular bonds, reduction of particle size, increase in surface area, formation of defects and local melting occur due to the kinetic energy supplied during grinding in solvent-free organic reactions based on grinding. The transfer of very small amounts of energy through friction in this process leads to more efficient mixing and close contact between the starting materials on a molecular scale. The grinding mode for the solid-state reactions has earlier been reported for Reformatsky reaction, ${ }^{4}$ Aldol condensation, Dieckmann condensation, Knoevenagel condensation, ${ }^{5}$ reduction, and others. ${ }^{6}$ Most of these reactions are carried out at room temperature in absolutely solvent-free environment using only a mortar and pestle. ${ }^{7}$ The unique structural features of Spirooxindoles ${ }^{8}$ together with varied biological activities have made them honored structures in new drug discovery. Among them, Spiro-pyrrolidinyl oxindoles have been extensively studied as potent inhibitors of p53-MDM2 interaction, finally leading to the identification of MI-888, which could achieve rapid, complete and durable tumor regression in xenograft models of human cancer with oral administration and is in advanced preclinical research for cancer therapy.

Several synthetic Spiroheterocycles containing both indole and pyran rings, possess anticonvulsant, analgesic, herbicidal, and antimicrobial activities. ${ }^{9-12}$ A number of papers have been published on Spiro indoles incorporating pyran nucleus which include synthesis of

a) Spiro[indole-pyranobenzopyrans] by Dandia et al. ${ }^{12}$

b) Spiro [benzo(H)chromene-4-(4H),3'(3-indole)]-2'-[H]-one by Aly Atta ${ }^{13}$

c) Spirocyclic (5,6,7,8-tetrahydro-4H-chromene)-4,3'-oxindole by Michail Elinson et al. ${ }^{14}$

d) Spirochromenes by Minoo ${ }^{15}$

e) Spiro indenopyran-indoles by Dandia et al. ${ }^{16}$

f) Spirooxindole derivatives in aqueous medium using $\mathrm{ZnS}$ nanoparticle as catalyst by Dandia et al. ${ }^{17}$ and

g) Spiro-oxindoles in the presence of acetonitrile by Majid et al., ${ }^{18}$ etc.

Some of the above mentioned conditions possess shortcomings such as longer reaction time, lower yields, elevated temperature, and formation of side products. These shortcomings led us to develop a safe, environmentally benign, and more efficient method for the synthesis of Spiro indole derivatives. Among nitrogen-containing heterocyclic compounds, thiazoles are of immense interest to medicinal and industrial chemists due to their diverse biological activities $^{19-25}$ such as antiglutamate, antiparkinson, antimicrobial, anthelmintic, anti-inflammatory, antihyperlipidemic, antihypertension and antioxidant properties as well as inhibition of enzymes such as acetylcholine esterase, aldose reductase, lipoxygenase, ATPase, and HCV helicase. It has been observed that the incorporation of more than one bioactive heterocyclic moiety into a single framework may result 
into the production of novel heterocycles with enhanced bioactivity. Hence, synthesis of compounds belonging to pyranothiazole series constituent was considered as an important area of research.

In view of the wide range of biological activities associated with indole derivatives and in continuation of our work to develop simple and expeditious procedures for the synthesis of organic compounds, ${ }^{26-30}$ we wish to report a highly efficient procedure for the synthesis of Spiro indole-pyranothiazole derivatives under solventfree conditions using grinding technique. Earlier, ${ }^{25}$ we synthesized these compounds in the presence of piperidine/ $\mathrm{NiO}$ nanoparticles as catalyst under microwave irradiation. The present work aimed to prepare spiro indole derivatives using green grindstone technique as well as structure elucidation of the prepared compounds using spectroscopic tools. The practical reaction conditions have been studied and compared with our earlier reported method ${ }^{25}$ in terms of reaction time, percentage yield and workup procedure.

\section{Experimental}

\section{Materials and instruments}

Isatin or 1H-indole-2,3-dione $\left(\mathrm{C}_{8} \mathrm{H}_{5} \mathrm{NO}_{2}\right)$, malononitrile $\left(\mathrm{C}_{3} \mathrm{H}_{2} \mathrm{~N}_{2}\right)$ and rhodanine $\left(\mathrm{C}_{3} \mathrm{H}_{3} \mathrm{NOS}_{2}\right)$ were purchased from Sigma Aldrich. All melting points were taken on Toshniwal Melting Point Apparatus. ${ }^{1} \mathrm{HNMR}$ and ${ }^{13} \mathrm{CNMR}$ spectra of the prepared spiro indol derivatives were recorded on a Bruker Avance II 400 NMR and Bruker Avance II 100 NMR Spectrometers using deuterated dimethyl sulfoxide (DMSO-D $)$ and deuterated chloroform $\mathrm{CDCl}_{3}$ as solvent and tetramethylsilane (TMS) as internal reference standard. Also, IR spectra of the prepared compounds were recorded in $\mathrm{KBr}$ desk on a Perkin Elmer Infrared L1600300 Spectrum, Two Li-Ta spectrophotometer, 09991423 power cord, manufactured by Perkin Elmer Life and Analytical Science, Shelton, CT, USA in the range of $4000-400 \mathrm{~cm}^{-1}$. Thin Layer Chromatography (TLC) was carried out on silica gel layers. The silica gel plates were activated at $100^{\circ} \mathrm{C}$ for one hour and stored in a desiccator. Iodine vapors and U. V. chamber were used for visualization of different separated spots on the plate.

\section{Grindstone technique}

An equimolar mixture of isatin, malononitrile, and rhodanine $(0.01 \mathrm{~mol})$ in one drop of piperidine was ground for $10-15$ minutes using a mortar and pestle of appropriate size. The initial syrupy reaction mixture solidifies within 15 minutes. It is washed with cold water (to remove impurities) when solid residue was separated out which was filtered, washed with water, dried and crystallized from ethanol to give product. The progress of reaction was monitored by TLC (Benzene: Petroleum Ether, 8:2).

\section{Results and discussion}

\section{Synthesis of spiro indol derivatives}

In this study, we report the development of a solvent-free mechanochemical ${ }^{31,32}$ approach for the multicomponent ${ }^{33,34}$ synthesis of a series of Spiro indole derivatives in one step by the reaction of isatin, malononitrile and rhodanine using grindstone chemistry technique as shown in Scheme I. The three starting compounds were mixed in a porcelain mortar at room temperature in the presence of few drops of piperidine and ground for 5-10 minutes. The progress of reaction was monitored by TLC when the reactants were found to have reacted completely in 10 minutes. This syrupy reaction mixture solidifies within 14-15 minutes indicating the completion of reaction to afford Spiro indole pyaranothiazole derivatives in excellent yields. The product could be isolated by just diluting the reaction mixture with ice cold water. This new process is simple, rapid, efficient and inexpensive method for the synthesis of wide range of indole derivatives under solvent-free and mild conditions, making it consistent with the principles of green chemistry. The overall process involves the Knoevenagel condensation ${ }^{35}$ of 2-thioxo-4-thiazolidinone with $1 \mathrm{H}$-indole-2,3-dione with the elimination of one water molecule (which makes reaction mixture homogeneous) followed by "in situ" Michael addition of malononitrile in a single operation as shown in the mechanistic equation (Scheme II). Michael reaction of malononitrile on exomethylene carbon is interesting as it can afford either a Michael adduct which can exist as such or converted into Spiro pyran system of C-3 of Oxindole (Scheme II).<smiles>[X]C[N+](=O)[O-]</smiles>

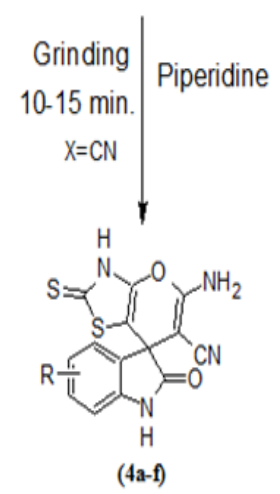

$\mathrm{R}=\mathrm{H} ; 5-\mathrm{Cl} ; 5-\mathrm{Br}$; $5-\mathrm{CH}_{3}: 5-\mathrm{NO}_{2}: 7-\mathrm{Cl}$
i. Compound No. (I): Isatin or IH-indole-2,3-dione $\left(\mathrm{C}_{8} \mathrm{H}_{5} \mathrm{NO}_{2}\right)$
ii. Compound No. (2): malononitrile $\left(\mathrm{C}_{3} \mathrm{H}_{2} \mathrm{~N}_{2}\right)$
iii. Compound No. (3): rhodanine or 2-thioxo-4-thiazolidinone $\left(\mathrm{C}_{3} \mathrm{H}\right.$ - ${ }_{3} \mathrm{NOS}_{2}$ )

iv. Compound No. (4a-f): Spiro \{indoline-3,4'-pyrano[2,3-c]thiazole\} carbonitrile derivatives

Earlier, we reported ${ }^{25}$ this reaction under microwave irradiation in the presence of 1-2 drops of piperidine as a catalyst. Reaction was completed within 8-10 minutes giving product yield of 70-80 $\%$ only. Further, reaction was also carried out under conventional heating which involved refluxing the reactants in absolute ethanol in the presence of 1-2 drops of piperidine for 13-14 hrs giving product yield of $50-60 \%$ only. Results are compared with that of our earlier reported method ${ }^{25}$ and found that grinding method is quite superior to conventional heating or microwave irradiation method as grinding takes only $14-15$ minutes with $80-92 \%$ yield of the product indicating that such reactions are cheaper to operate and are more economical in organic synthesis. Encouraged by these results, we have extended this reaction to variously substituted $1 \mathrm{H}$-indole-2,3-diones under similar conditions to furnish the respective spiro indole derivatives in excellent yields (80-90\%). Substituted groups, \% yield, and melting point of all prepared spiro indole derivatives were summarized 
in Table 1. It's clear from this table that the maximum yields were obtained with compound $4 \mathrm{f}$ which has nito-group $\left(\mathrm{NO}_{2}\right)$ in position 5 of indole molecule. Again, compound $4 \mathrm{f}$ has high melting point of $340^{\circ} \mathrm{C}$. From the data presented in Table 1, it can concluded that both the $\%$ yield and melting point of the prepared compounds were affected greatly by the chemical nature of substituted group $(\mathrm{R})$ in isatin or $1 \mathrm{H}$-indole-2,3-dione.

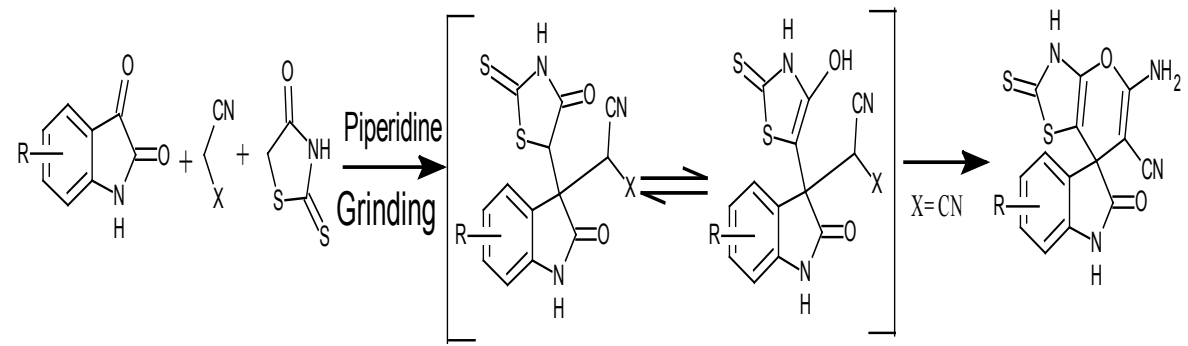

Scheme 2 Plausible mechanistic equation for the reaction of $\mathrm{IH}$-indole-2,3-dione and malononitrile with 2-thioxo-4-thiazolidinone.

Table I Substituted groups, \% yield and Melting point of prepared spiro indole derivatives

\begin{tabular}{|c|c|c|c|c|}
\hline Compound & $\mathbf{R}$ & $\begin{array}{l}\text { Time } \\
\text { (min) }\end{array}$ & Yield (\%) & M.P. $\left({ }^{\circ} \mathrm{C}\right)^{25}$ \\
\hline $4 a$ & $\mathrm{H}$ & 15 & 90 & 298 \\
\hline $4 b$ & $5-\mathrm{Cl}$ & 15 & 87 & 310 \\
\hline $4 c$ & $5-\mathrm{Br}$ & 15 & 88 & 270 \\
\hline $4 d$ & $5-\mathrm{CH}_{3}$ & 15 & 88 & 315 \\
\hline $4 e$ & $7-\mathrm{Cl}$ & 15 & 90 & 275 \\
\hline $4 f$ & $5-\mathrm{NO}_{2}$ & 15 & 92 & 340 \\
\hline
\end{tabular}

\section{Structure elucidation of spiro indol derivatives}

IR, ${ }^{1} \mathrm{HNMR}$, and ${ }^{13} \mathrm{CNMR}$ charts were obtained for the prepared methylated spiro indole derivative (compound $4 \mathrm{~d}$ ) as shown in (Figure 1). IR spectra of this compound displayed characteristic absorption bands in the region $3450-3310 \mathrm{~cm}^{-1}\left(\mathrm{NH}\right.$ str. of $\left.\mathrm{NH}_{2}\right), 3265-3115 \mathrm{~cm}^{-1}$ (NH str.), 3059-3008 $\mathrm{cm}^{-1}$ (aromatic C-H str.), 2235-2120 $\mathrm{cm}^{-1}(\mathrm{C} \equiv \mathrm{N})$ and $1720-1685 \mathrm{~cm}^{-1}(\mathrm{C}=\mathrm{O})$. Although the reaction proceeds via condensation, there is no broad band appeared in the region 3000$3500 \mathrm{~cm}^{-1}$ indicating that the analyzed compound is water-free and can be described as completely dry compound. This observation may be explained by the evaporation of very small amount of physically adsorbed water molecules during grinding and analysis process. ${ }^{1} \mathrm{HNMR}$ spectrum of $4 \mathrm{~d}$ showed singlets at $\delta 10.91$ due to $\mathrm{NH}$ of indole, multiplet at 6.81-8.02 due to $3 \mathrm{H}$ of aromatic ring, singlet at 8.65 due to $\mathrm{NH}_{2}$ of amino group, singlet at 2.84 due to $\mathrm{NH}$ of thiazolidinone ring and singlet at 2.11 due to $3 \mathrm{H}$ of $\mathrm{CH}_{3}$ group at $5^{\text {th }}$ position of indole ring. Formation of compound $4 \mathrm{~d}$ was further confirmed on the basis of ${ }^{13} \mathrm{CNMR}$ spectrum. In ${ }^{13} \mathrm{CNMR}$ spectrum, sharp signals were observed at $\delta 191.54(\mathrm{C}=\mathrm{S}), 183.42\left(\mathrm{C}-\mathrm{NH}_{2}\right), 169.40(\mathrm{C}=\mathrm{O}), 144.97$ 121.00 (aromatic carbon), 117.14 $(\mathrm{C} \equiv \mathrm{N}), 59.64$ (Spiro carbon) and $22.43 \mathrm{ppm}\left(\mathrm{CH}_{3}\right)$. All spectral data for compound $4 \mathrm{~d}$ is summarized in Table 2.

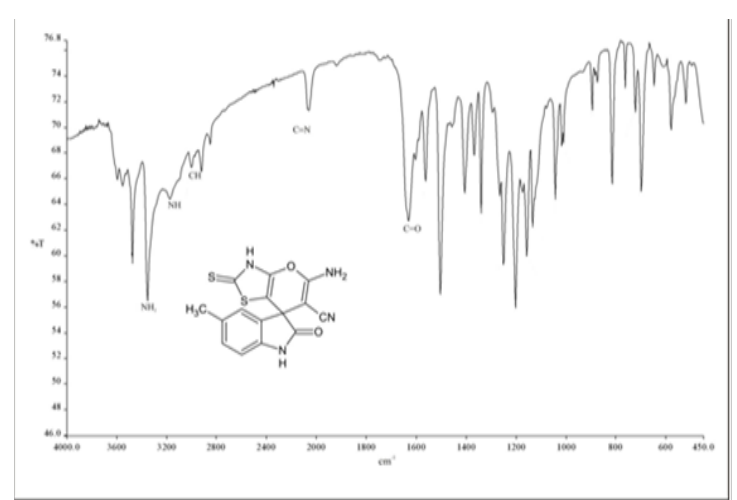

IR Spectrum

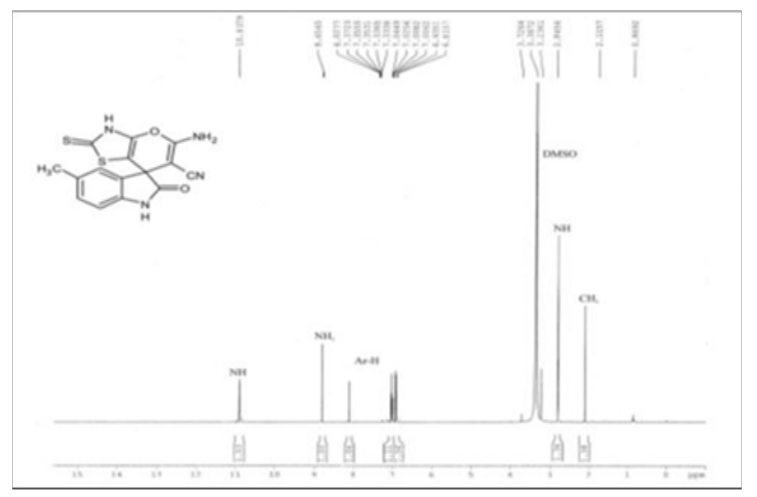

'H NMR Spectrum

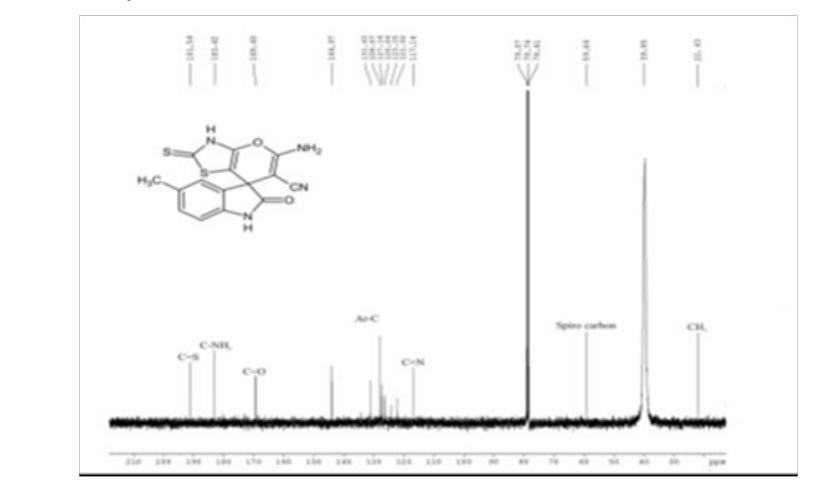

${ }^{13}$ C NMR Spectrum

Figure I Spectral analysis of Spiro indole derivatives (compound 4d). Compound 4d: 6'-Amino-2' -thioxo-5-methyl-2-oxo- I'H-spiro indoline-3, $4^{\prime}$-pyrano $[2,3 c]$ thiazole $\}-5^{\prime}$-carbonitrile. 
Table 2 Spectral data of Spiro indole derivative (compound 4d)

\begin{tabular}{|c|c|c|c|}
\hline Entry & IR $\left(\mathrm{cm}^{-1}\right)$ & 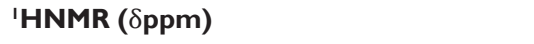 & ${ }^{13}$ CNMR ( $\delta$ ppm) \\
\hline $4 d$ & $\begin{array}{l}3350\left(\mathrm{NH}_{2}\right), 3 \mathrm{I} 25(\mathrm{NH}) \\
3042-3008 \text { (aromatic C-H } \\
\text { str), } 2120(\mathrm{CN}), 1689(\mathrm{CO})\end{array}$ & $\begin{array}{l}\text { I0.9I (s, IH, NH indole), } 8.65\left(\mathrm{~s}, 2 \mathrm{H}, \mathrm{NH}_{2}\right) \\
6.8 \mathrm{I}-8.02(\mathrm{~m}, 3 \mathrm{H}, \mathrm{Ar}-\mathrm{H}), 2.84(\mathrm{~s}, \mathrm{IH}, \mathrm{NH}), 2 . \mathrm{I} \\
\left(\mathrm{s}, 3 \mathrm{H}, \mathrm{CH}_{3}\right)\end{array}$ & 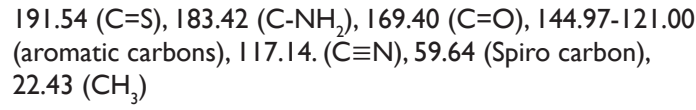 \\
\hline
\end{tabular}

\section{Conclusion}

A simple, faster and efficient protocol for the synthesis of Spiro indole derivatives involving grinding of different Isatins, malononitrile and rhodanine in the presence of piperidine at room temperature under solvent-free conditions is described. This procedure is also consistent with green chemistry approach as no solvent is required (except for recrystallization). Higher yields compared to the conventional method are the advantages of present protocol. Reaction gets completed within 15 minutes in the absence of any solvent in contrast to conventional heating method making it cost effective as it does not require harsh reagents. Reaction can be easily carried out in organic chemistry research laboratory using porcelain mortar.

\section{Acknowledgements}

The authors are thankful to the Dean, Prof. Atul Kumar, CASH, MUST, Laxmangarh (Sikar), Rajasthan, India for providing support and necessary research facilities in the department.

\section{Conflict of interest}

The author declares no conflict of interest.

\section{References}

1. Kumar JS, Shabeer TK. Multicomponent Biginelli Synthesis of 3,4-dihydropyrimidin-2(1H)-ones by grindstone technique and evaluation of their biological properties. J Chem Pharm Res. 2011;3(6):1089-1096.

2. Bose AK, Pednekar S, Ganguly SN, et al. A simplified green chemistry approach to the Biginelli reaction using 'Grindstone Chemistry'. Tetrahedron letters. 2004;45(45):8351-8353.

3. Tanaka K, Kishigami S, Toda F. Reformatsky and Luche reaction in the absence of Solvent. J Org Chem. 1991;56(13):4333-4334.

4. Ren ZJ, Cao WG, Tong WQ1. The Knoevengel condensation reaction of aromatic aldehydes with malononitrile by grinding in the absence of solvents and catalysts. Synth Commun. 2002;32(22):3475-3479.

5. Ren Z, Cao W, Tong W, et al. Solvent-Free, One-Pot Synthesis of Pyrano [2, 3-c]pyrazole Derivatives in the Presence of $\mathrm{KF} \cdot 2 \mathrm{H}_{2} \mathrm{O}$ by Grinding. Synth Commu. 2005;35(19):2509-2513.

6. Satish K, Poonam S, Kamal K, et al. An efficient, catalyst and solventfree, four-component, and one-pot synthesis of polyhydroquinolines on grinding. Tetrahedron. 2008;64(13):536-542.

7. Yu B, Yu DQ, Liu HM. Spirooxindoles: Promising scaffolds for anticancer agents. Eur J Med Chem. 2015;97:673-698.

8. Nazari P, Bazi A, Ayatollahi SA, et al. Synthesis and evaluation of the antimicrobial activity of spiro-4H-pyran derivatives on some gram positive and gram negative bacteria. Iranian Journal of Pharmaceutical Research. 2017;16(3):943-952.

9. Joshi KC, Jain R, Sharma K, et al. Synthesis and biological activity of spiro[indole-3, $8^{\prime}$-phenaleno[1,2-b]pyran]-9'-carbonitriles and spiro[indole-3,4'-pyrano[4,3-b]pyran]-3'-carbonitriles by one-pot, three-component reactions. J Indian Chem Soc. 1988;65:202-206.
10. Joshi KC, Jain R, Arora S. Synthesis and biological activity of novel fluorine containing spiro[3H-indole-3,5'- $(5 \mathrm{H})$ pyrano[2,3-d] pyrimidine]-6'-carbonitriles and ethyl carboxylates. Heterocycles. $1990 ; 31: 31-36$

11. Nandakumar A, Thirumurugan P, Perumal PT, et al. One-pot multicomponent synthesis and anti-microbial evaluation of 2'-(indol-3-yl)-2oxospiro (indoline-3,4'-pyran) derivatives. Bioorg Med Chem Lett. 2010;20:4252-4258.

12. Dandia A, Singha R, Sachdeva H, et al. Microwave promoted and improved thermal synthesis of spiro[indole-pyranobenzopyrans] and spiro[indole-pyranoimidazoles]. J Chin Chem Soc. 2003;50(2):273278

13. Aly Atta H. Synthesis of some heterocyclic compounds from $1 \mathrm{H}-$ indole-2,3-dione: A direct one-pot synthesis of spiro indolone derivatives. $J$ Chem Soc. 2006;53(3):663-667.

14. Michail Elinson N, Alexey Ilovaisky I, Alexander Dorofeev S, et al. Electrocatalytic multicomponent transformation of cyclic 1,3-diketones, isatins, and malononitrile: facile and convenient way to functionalized spirocyclic (5,6,7,8-tetrahydro-4H-chromene)-4,3'-oxindole system. Tetrahedron. 2007;63(42):10543-10548.

15. Minoo D, Mahboobeh B, Mostafa B. Ammonium salt catalyzed multicomponent transformation:simple route to functionalized spirochromenes and spiroacridines. Tetrahedron. 2009;65(45):9443-9447.

16. Dandia A, Singh R, Singh D. Facile one-pot synthesis of new annulated hexacyclic ring system indeno-pyranofuro-indoles and spiro indenopyran-indoles under microwave irradiation. Indian J Chem. 2009;48B:1001-1005.

17. Dandia A, Parewa V, Jain AK, et al. Step-economic, efficient, ZnS nanoparticle-catalyzed synthesis of spirooxindole derivatives in aqueous medium via Knoevenagel condensation followed by Michael addition. Green Chem. 2011;13(8):2135-2145.

18. Majid MH Masoumeh Z, Arezoo M. Versatile three-component procedure for combinatorial synthesis of spiro-oxindoles with fused chromenes catalysed by L-proline. J Chem Sci. 2012;124(4):865-869.

19. Mohammed Iqbal AK, Khan AY, Kalashetti MB, et al. Synthesis, hypoglycemic and hypolipidemic activities of novel thiazolidinedione derivatives containing thiazole/triazole/oxadiazole ring. Eur J Med Chem. 2012;53:308-315.

20. Kashyap SJ, Garg VK, Sharma PK, et al. Thiazoles: having diverse biological activities. Medicinal Chemistry Research. 2012;21(8):21232132 .

21. Bouherrou H, Saidoun A, Abderrahmani A, et al. Synthesis and Biological Evaluation of New Substituted Hantzsch Thiazole Derivatives from Environmentally Benign One-Pot Synthesis Using Silica Supported Tungstosilisic Acid as Reusable Catalyst. Molecules. 2017;22(5):757.

22. Xie Z, Wang G, Wang J, et al. Synthesis, Biological Evaluation, and Molecular Docking Studies of Novel Isatin-Thiazole Derivatives as $\alpha-$ Glucosidase Inhibitors. Molecules. 2017;22(4):E659.

23. Rawat BS, Shukla SK. Synthesis and Evaluation of some New Thiazole/ Oxazole Derivatives for their Biological Activities. World Journal of Pharmacy and Pharmaceutical Sciences. 2016;5:1473-1482. 
24. Mishra R, Sharma PK, Verma PK, et al. Biological Potential of Thiazole Derivatives of Synthetic Origin. Journal of Heterocyclic Chemistry. 2017;54(4):2103-2116.

25. Harshita S, Dwivedi D, Bhattacharjee RR, et al. NiO nanoparticles: an efficient catalyst for the multi-component one-pot synthesis of novel spiro and condensed indole derivatives. Journal of Chemistry. 2012;2013:1-10.

26. Sachdeva H, Saroj R, Dwivedi D. Nano-ZnO Catalyzed Multi-component One-Pot Synthesis of Novel Spiro (indoline-pyranodioxine) Derivatives. Scientific World Journal. 2014;2014:427195.

27. Sachdeva H, Dwivedi D. Lithium-acetate-mediated biginelli one-pot multi-component synthesis under solvent-free conditions and cytotoxic activity against the human lung cancer cell line A549 and breast cancer cell line MCF7. The Scientific World Journal. 2012;2012:1-9.

28. Sachdeva H, Dwivedi D, Saroj R. Alum catalyzed simple, efficient, and green synthesis of 2-[3-amino-5-methyl-5-(pyridin-3-yl)-1, 5-dihy dro-4H-1, 2, 4-triazol-4-yl] propanoic acid derivatives in aqueous media. The Scientific World Journal. 2013;2013:1-7.

29. Sachdeva H, Saroj R, Khaturia S, et al. Operationally simple green synthesis of some Schiff bases using grinding chemistry technique and evaluation of antimicrobial activities. Green processing and Synthesis. 2012;1(5):469-477.
30. Sachdeva H, Dwivedi D, Arya K, et al. Synthesis, anti-inflammatory activity, and QSAR study of some Schiff bases derived from 5-mercapto-3-(4'-pyridyl)-4H-1, 2, 4-triazol-4-yl-thiosemicarbazide. Medicinal Chemistry Research. 2013;22(10):4953-4963.

31. Raj T, Hemant S, Ajnesh S, et al. "Solvent-Less" Mechanochemical Approach to the Synthesis of Pyrimidine Derivatives. ACS Sustainable Chemistry \& Engineering. 2017;5(2):1468-1475.

32. Klimakow M, Klobes $\mathrm{P}$, Thünemann AF, et al. Mechanochemical synthesis of metal- organic frameworks: a fast and facile approach toward quantitative yields and high specific surface areas. Chemistry of Materials. 2010;22(18):5216-5221.

33. Abbas EM, Gomha SM, Farghaly TA. Multicomponent reactions for synthesis of bioactive polyheterocyclic ring systems under controlled microwave irradiation. Arabian Journal of Chemistry. 2014;7(5):623629.

34. Gunasekaran P, Menéndez JC, Perumal S. Synthesis of Heterocycles through Multi-component Reactions in Water. Green Chemistry: Synthesis of Bioactive Heterocycles. 2014:1-35.

35. Dandia A, Singha R, Sachdeva H, et al. Microwave promoted and improved thermal synthesis of spiro[indole-pyranobenzopyrans] and spiro[indole-pyranoimidazoles]. J Chin Chem Soc. 2003;50(2):273-278. 